ISSN 1981-416X

\title{
Formação pedagógica na docência universitária: o que pensam professores pesquisadores portugueses
}

\section{Pedagogical training for higher education teachers: what Portuguese researcher-teachers think of it}

\author{
La formación del profesorado en la enseñanza \\ universitaria: lo que piensan los investigadores \\ profesores portugueses
}

\author{
Marilda Aparecida Behrens ${ }^{[a]}$, Kelen dos Santos Junges ${ }^{[b]^{*}}$ \\ [a] Pontifícia Universidade Católica do Paraná (PUCPR), Curitiba, PR, Brasil \\ [b] Universidade Estadual do Paraná (UNESPAR) - Campus de União da Vitória, União da Vitória, PR, Brasil
}

\section{Resumo}

O atual contexto universitário requer um novo perfil profissional nos docentes do ensino superior, demandando, além do conhecimento científico da área em que atuam, um repensar sobre a forma de organização do processo de ensino e aprendizagem, numa perspectiva pedagógica. Com este desafio posto, buscou-se investigar o problema: Quais as 
concepções dos professores portugueses para embasar uma formação pedagógica? Esta problemática gerou o objetivo desta pesquisa: Investigar e apresentar a visão de professores portugueses sobre a formação pedagógica para a docência no ensino superior. Ligadas a uma fase exploratória de pesquisa do doutorado, as 14 entrevistas apresentadas ocorreram durante um período de estágio. doutoral, com bolsa Capes, em Portugal, no Instituto de Educação da Universidade de Lisboa. Os professores entrevistados foram escolhidos porque são autores portugueses presentes na literatura, os quais apresentam em suas pesquisas o tema formação de professores, disponíveis no Brasil. Como instrumento de coleta de dados, utilizou-se uma entrevista semiestruturada com apoio de um guião focado nos temas a serem investigados. A categorização dos dados das entrevistas revela que as instituições de ensino superior precisam tornar-se o lócus dessa formação, a partir de processos formativos focados numa pedagogia universitária. Por outro lado, é importante que o docente universitário esteja convencido da importância da formação pedagógica e de seu desenvolvimento profissional e, para tanto, se disponham a melhorar sua prática para transformar a educação, a instituição, seus alunos e a si mesmo como profissional.

Palavras-chave: Docência Universitária. Formação Pedagógica. Contribuições de Pesquisadores Portugueses.

\begin{abstract}
The current university context requires a new professional profile of higher education teachers, demanding, in addition to the scientific knowledge of the area in which they operate, a rethinking of the way of organizing the process of teaching and learning, in a pedagogical perspective. With this challenge in mind, we sought to investigate the issue: What are the concepts of Portuguese teachers to support a teacher training? This problem generated the research objective: To investigate and present the vision of Portuguese teachers about pedagogical training for teaching in higher education. Linked to an exploratory phase of doctoral research, the fourteen interviews presented occurred during a doctoral training period, with Capes scholarship, in Portugal, at the Instituto de Educação da Universidade de Lisboa (Institute of Education, University of Lisbon). The teachers who were interviewed were chosen because they are Portuguese authors who write about teacher training and their
\end{abstract}


theories are available in Brazil. The data collection instrument used was a semi-structured interview with the support of a guide focused on the issues to be investigated. The categorization of the interview data reveals that higher education institutions need to become the locus of such training, from training processes focused on university pedagogy. On the other hand, it is important that university teachers are convinced of the importance of teacher training and professional development and, therefore, are willing to improve their practice to transform education, the institution, the students and themselves as professionals.

Keywords: University Teaching. Teacher Education Training. Contributions of Portuguese Researchers.

\section{Resumen}

El contexto universitario actual requiere un nuevo perfil profesional de los profesores de enseñanza superior, exigiendo, además del conocimiento científico de la zona en la que operan, un replanteamiento de la forma de organizar el proceso de enseñanza y aprendizaje, una perspectiva pedagógica. Con este reto que plantea trató de investigar la cuestión: ¿Cuáles son los conceptos de profesores portugueses para apoyar una formación pedagógica? Este problema ha generado el objetivo de esta investigación: investigar y presentar la visión de los profesores portugueses sobre la formación pedagógica para la enseñanza en la educación superior. En una fase exploratoria de doctorado, las 14 entrevistas presentadas tuvieron lugar durante un período de formación doctoral, con la Capes, el Instituto de Educación de la Universidad de Lisboa. Los maestros entrevistados fueron elegidos porque están presentes en la literatura brasileña que tienen que ver con la formación del profesorado. Dado que la recopilación de datos instrumento utilizado fue una entrevista semiestructurada con el apoyo de una guía centrada en las cuestiones que deben investigarse. La categorización de los datos de las entrevistas revela que las instituciones de educación superior necesitan para convertirse en el lugar de dicha formación, a partir de los procesos de formación centrados en la pedagogía universitaria. Por otro lado, es importante que los profesores universitarios están convencidos de la importancia de la formación del profesorado y el desarrollo profesional y, por lo tanto, están dispuestos a 
mejorar su práctica para transformar la educación, la institución, los estudiantes y como un profesional.

Palavras clave: La enseñanza universitaria. Formación de Maestros. Las contribuciones de los investigadores portugueses.

\section{Introdução}

$\mathrm{O}$ atual contexto universitário requer um novo perfil profissional dos docentes do ensino superior, demandando, além do conhecimento científico da área em que atuam, um repensar sobre a forma de organização do processo de ensino e aprendizagem, numa perspectiva pedagógica.

Fica evidente que a Universidade em sua completude, incluindo os professores, precisa preparar-se para transformar essa nova realidade. Isso requer um novo perfil profissional dos docentes do ensino superior, demandando, além do conhecimento científico da área em que atuam, uma nova concepção paradigmática na docência advinda do movimento da Ciência e da Educação, o que exige um repensar sobre a forma de organização do processo de ensino e aprendizagem. O ensinar e o aprender, hoje, na universidade, exigem superar a reprodução na busca da produção do conhecimento e, para tanto, há necessidade de oferecer processos mais flexíveis e dinâmicos de aprendizagem, menos rígidos e mais receptivos a inovações, à pesquisa e à comunicação, almejando oportunizar a conquista de melhor qualidade de vida aos alunos.

Nesse sentido, compreende-se a importância da formação dos professores universitários para atender a essa nova demanda e, este desafio, envolve "o que escolher" para oferecer uma formação pedagógica da Educação Superior. A partir do atual contexto do ensino superior, destaca-se a importância de se analisar a contribuição da formação pedagógica, numa perspectiva reflexiva, para o desenvolvimento profissional de docentes do Ensino Superior e as possíveis repercussões dessa formação para 
uma prática pedagógica inovadora de professores (BEHRENS, 2007). Com este objeto de investigação, as autoras se propuseram a organizar um programa de formação para professores universitários em uma Instituição de Educação Superior Pública Municipal de União da Vitória/PR/Brasil ${ }^{1}$.

Com isto posto, buscou-se investigar o problema: Quais as concepções dos professores portugueses para embasar uma formação pedagógica? Em busca de respostas para esta problematização, objetivou-se investigar e apresentar a visão de professores portugueses sobre a formação pedagógica para a docência no ensino superior. Portanto, a partir de pesquisas já realizadas nas diferentes fases dos estudos da tese produzidos no Brasil, optou-se por desenvolver uma fase de pesquisa exploratória para investigar também as experiências que são realizadas em outras universidades e, especialmente, no contexto europeu. A esse respeito, Esteves (2008, p. 108), salienta que o desenvolvimento de programas/propostas de formação pedagógica, envolvendo docentes de diversas instituições (nacionais ou estrangeiras) pode trazer "estímulos importantes para a construção da excelência pedagógica do ensino superior". Justifica-se a opção pela realidade portuguesa, uma vez que este país possui autores com obras amplamente divulgadas no Brasil, muito reconhecidos na área da formação de professores e com recentes pesquisas na área da docência no ensino superior.

Assim, esta fase de pesquisa exploratória apresentada neste texto envolveu entrevistas com quinze autores portugueses escolhidos, a partir de suas experiências, que foram realizadas durante um período de estágio doutoral (Doutorado Sanduíche), com bolsa Capes, no Instituto de Educação da Universidade de Lisboa. As entrevistas tinham como finalidade também fundamentar uma fase posterior, ou seja, buscar subsídios para a organização e orientação de um programa de formação pedagógica para professores universitários de uma instituição de ensino superior pública municipal brasileira. Os contatos com professores universitários portugueses foram agendados e as entrevistas foram realizadas com estes

\footnotetext{
${ }^{1}$ Este programa de formação pedagógica faz parte de pesquisa de tese (JUNGES, 2013).
} 
pesquisadores por meio de um guião ${ }^{2}$. As entrevistas foram gravadas para posterior análise, conforme a autorização dos entrevistados.

A categorização dos dados das entrevistas dos professores pesquisadores portugueses revela que as instituições de ensino superior precisam tornar-se o lócus dessa formação, a partir de uma pedagogia universitária. Por outro lado, é importante que os docentes universitários estejam convencidos da importância da formação pedagógica e se disponham a melhorar sua prática em prol do desenvolvimento profissional, da educação, da instituição, dos estudantes e de si mesmo como profissional.

\section{Contribuições de pesquisadores portugueses sobre a docência universitária e a formação pedagógica}

A partir do atual contexto do ensino superior, as autoras se propuseram a levantar as contribuições de autores portugueses que vem fundamentando as investigações sobre formação pedagógica de professores em Portugal e no Brasil.

As falas dos pesquisadores entrevistados estão identificadas por seus respectivos sobrenomes. Este procedimento justifica-se pela relevância das pesquisas realizadas pelos participantes, pois se fossem indicados apenas por códigos, para salvaguardar o anonimato, não seria possível identificar a contribuição que foi levantada a partir dos critérios selecionados. Assim, tomou-se o cuidado de pedir a autorização por escrito para utilizar o nome próprio na pesquisa, fato que foi aceito e autorizado por escrito pelos pesquisadores envolvidos.

Como se pode perceber no Quadro 1, ao iniciar a pesquisa em Portugal foi possível localizar os pesquisadores que além da Universidade de Lisboa, envolveu a Universidade Nova de Lisboa, a Universidade Católica Portuguesa, a Universidade de Aveiro, da Universidade do Porto

2 O guião constitui-se em um roteiro de entrevista criado por Estrela (1986) e comumente adotado em pesquisas portuguesas. 
e Universidade do Minho. Esta escolha se derivou da constatação de experiências, projetos e estudos realizados por estes pesquisadores sobre a formação de professores universitários nessas Universidades.

Quadro 1 - Relação de professores investigadores portugueses entrevistados.

(continua)

\begin{tabular}{|c|c|c|}
\hline Instituição & Entrevistado & Atuação Profissional \\
\hline \multirow{5}{*}{$\begin{array}{l}\text { Universidade } \\
\text { de Lisboa (UL) }\end{array}$} & $\begin{array}{l}\text { 1. Prof.a Dra. Manuela } \\
\text { Esteves }\end{array}$ & $\begin{array}{l}\text { Professora do IEUL, pesquisadora das áreas de } \\
\text { Currículo e de Formação de Professores. }\end{array}$ \\
\hline & $\begin{array}{l}\text { 2. Prof. Dr. António } \\
\text { Nóvoa }\end{array}$ & $\begin{array}{l}\text { Reitor emérito da UL, pesquisador das áreas de } \\
\text { História da Educação, Educação Comparada e } \\
\text { Formação de Professores. }\end{array}$ \\
\hline & $\begin{array}{l}\text { 3. Prof.a Dra. Ângela } \\
\text { Rodrigues }\end{array}$ & $\begin{array}{l}\text { Professora do IEUL, pesquisadora das áreas de } \\
\text { Currículo e de Formação de Professores. }\end{array}$ \\
\hline & $\begin{array}{l}\text { 4. Prof. a Dra. Maria } \\
\text { Teresa Estrela }\end{array}$ & $\begin{array}{l}\text { Professora Catedrática do IEUL, pesquisadora das } \\
\text { áreas de Currículo e de Formação de Professores. }\end{array}$ \\
\hline & $\begin{array}{l}\text { 5. Prof. a Dra. Ana Paula } \\
\text { Caetano }\end{array}$ & $\begin{array}{l}\text { Professora do IEUL, pesquisadora das áreas de } \\
\text { Currículo e de Formação de Professores. }\end{array}$ \\
\hline $\begin{array}{l}\text { Universidade } \\
\text { Nova de } \\
\text { Lisboa (UNL) }\end{array}$ & $\begin{array}{l}\text { 6. Prof.a Dra. Patrícia } \\
\text { Rosado Pinto }\end{array}$ & $\begin{array}{l}\text { Diretora do Departamento de Educação Médica da } \\
\text { Faculdade de Ciências Médicas da UNL. }\end{array}$ \\
\hline \multirow{2}{*}{$\begin{array}{l}\text { Universidade } \\
\text { Católica } \\
\text { Portuguesa } \\
\text { (UCP - Lisboa) }\end{array}$} & $\begin{array}{l}\text { 7. Prof.a Dra. Maria do } \\
\text { Céu Roldão }\end{array}$ & $\begin{array}{l}\text { Professora da UCP, pesquisadora e consultora da área } \\
\text { de Formação de Professores. }\end{array}$ \\
\hline & $\begin{array}{l}\text { 8. Prof. Dr. Rodrigo } \\
\text { Queiroz e Mello }\end{array}$ & $\begin{array}{l}\text { Professor e Membro do Conselho de Direcção da } \\
\text { Escola de Lisboa da Faculdade de Direito da UCP. } \\
\text { Coordena a reforma curricular e a avaliação da escola. }\end{array}$ \\
\hline \multirow[t]{2}{*}{$\begin{array}{l}\text { Universidade } \\
\text { de Aveiro (UA) }\end{array}$} & 9. Prof. Dr. José Tavares & $\begin{array}{l}\text { Professor Catedrático jubilado da UA, pesquisador da } \\
\text { área de Formação de Professores. Coordena uma linha } \\
\text { de investigação do CIDInE (Centro de Investigação, } \\
\text { Difusão e Intervenção Educacional) sobre "Docência e } \\
\text { Inovação no Ensino Superior". }\end{array}$ \\
\hline & $\begin{array}{l}\text { 10. Prof. a Dra. Isabel } \\
\text { Alarcão }\end{array}$ & $\begin{array}{l}\text { Professora Catedrática da UA (aposentada), } \\
\text { pesquisadora da área de Formação de Professores. }\end{array}$ \\
\hline
\end{tabular}


Quadro 1 - Relação de professores investigadores portugueses entrevistados.

(conclusão)

\begin{tabular}{|c|c|c|}
\hline \multirow{4}{*}{$\begin{array}{l}\text { Universidade } \\
\text { do Porto (UP) }\end{array}$} & $\begin{array}{l}\text { 11. Prof. Dr. Rui } \\
\text { Trindade }\end{array}$ & $\begin{array}{l}\text { Professor da UP, pesquisador da área de Formação de } \\
\text { Professores. }\end{array}$ \\
\hline & $\begin{array}{l}\text { 12. Prof. a Dra. Preciosa } \\
\text { Fernandes }\end{array}$ & $\begin{array}{l}\text { Professora da UP, pesquisadora das áreas de Currículo } \\
\text { e de Formação de Professores. }\end{array}$ \\
\hline & $\begin{array}{l}\text { 13. Prof. a Dra. Ana } \\
\text { Mouraz }\end{array}$ & $\begin{array}{l}\text { Professora da UP, pesquisadora da área de formação } \\
\text { de professores. Pertence ao Laboratório de Ensino e } \\
\text { Aprendizagem (LEA) que é uma organização conjunta } \\
\text { da Faculdade de Engenharia e da Faculdade de } \\
\text { Psicologia e de Ciências da Educação da UP, que se } \\
\text { dedica à formação dos professores universitários. }\end{array}$ \\
\hline & $\begin{array}{l}\text { 14. Prof. a Dra. Ana } \\
\text { Mouraz }\end{array}$ & $\begin{array}{l}\text { Professora da UP, pesquisadora da área de formação } \\
\text { de professores. Pertence ao Laboratório de Ensino e } \\
\text { Aprendizagem (LEA) que é uma organização conjunta } \\
\text { da Faculdade de Engenharia e da Faculdade de } \\
\text { Psicologia e de Ciências da Educação da UP, que se } \\
\text { dedica à formação dos professores universitários. }\end{array}$ \\
\hline $\begin{array}{l}\text { Universidade } \\
\text { do Minho } \\
\text { (UM) }\end{array}$ & $\begin{array}{l}\text { 15. Prof. a Dra. Flávia } \\
\text { Vieira }\end{array}$ & $\begin{array}{l}\text { Professora e coordenadora dos Mestrados em Ensino } \\
\text { e do Estágio Profissional da UM, pesquisadora } \\
\text { das áreas de formação de professores, supervisão } \\
\text { pedagógica e pedagogia para a autonomia. Coordenou } \\
\text { projetos de formação de professores da UM. }\end{array}$ \\
\hline
\end{tabular}

Fonte: Elaborado pelas autoras, 2011.

As descobertas produzidas nessas entrevistas junto aos pesquisadores portugueses ${ }^{3}$, subsidiaram a análise dos dados coletados, que foram organizados em três dimensões de categorização: a percepção em relação à formação do docente do Ensino Superior; a formação pedagógica para a docência universitária e dispositivos de formação pedagógica. A tessitura das contribuições gerou este artigo, com o propósito de entrelaçar as relevantes participações dos professores portugueses envolvidos no estudo.

A Figura 1 ilustra as dimensões e as categorias, bem como os elementos definidores demarcados na análise das entrevistas:

${ }^{3}$ As falas destacadas das entrevistas são apresentadas em itálico para diferenciá-las do restante das citações oriundas da literatura. Os textos das entrevistas gravadas foram revistos pelos professores entrevistados, a fim de evitar possíveis falhas de transcrição e foi autorizada, por escrito, a indicação de seus nomes na publicação, por meio de Termo de Consentimento Livre e Esclarecido. 
Figura 1 - Dimensões, categorias e elementos definidores da formação pedagógica segundo pesquisadores portugueses entrevistados

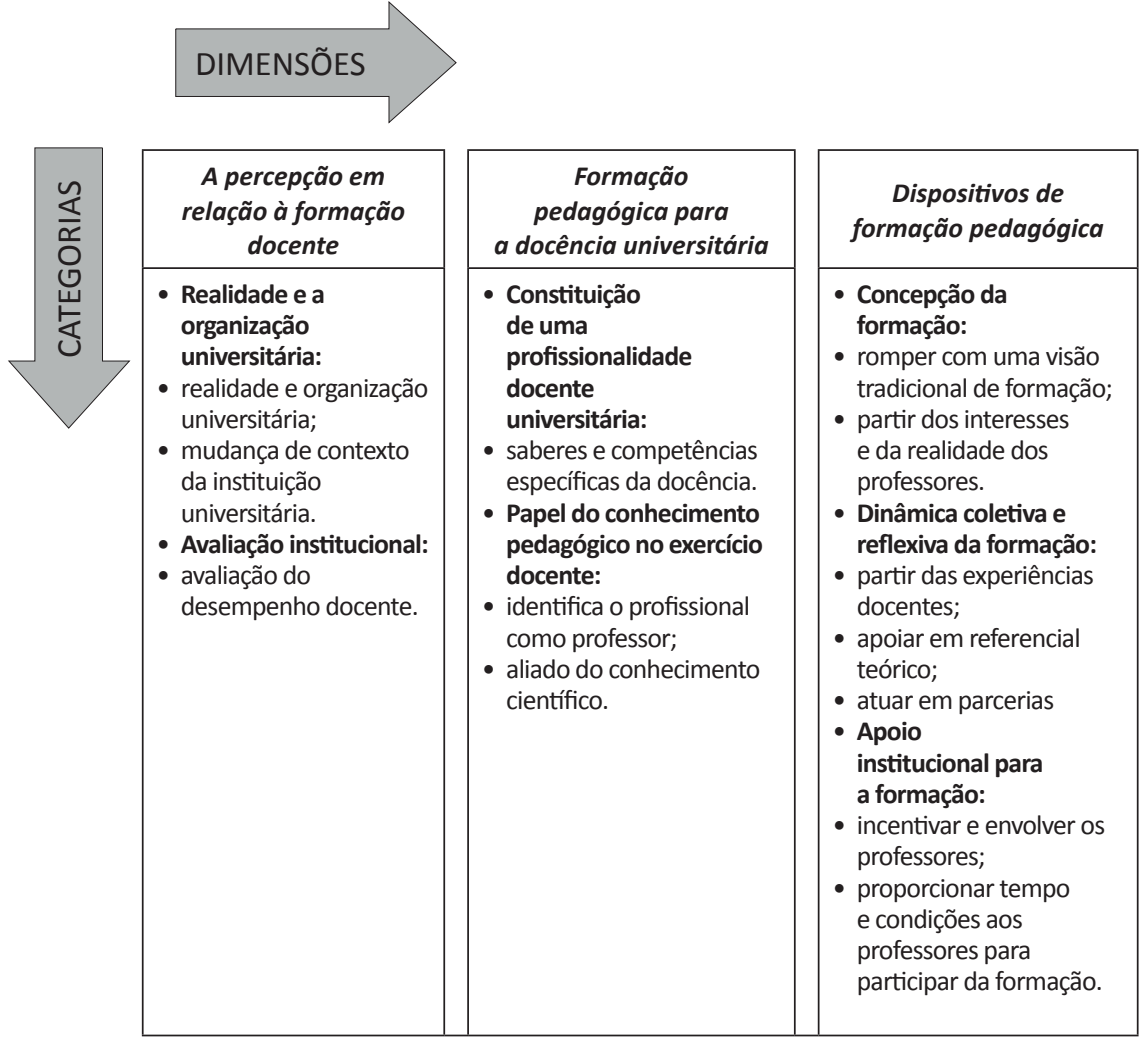

Fonte: Elaborado pelas autoras, 2011.

A dimensão da percepção em relação à formação do docente do Ensino Superior, conforme a Figura 1, tem como categorias: a realidade e a organização universitária e a avaliação institucional. Os professores, em unanimidade, destacaram que a discussão a respeito da formação dos professores universitários é ainda recente em Portugal e que surgiu, em grande parte, devido à realidade e a organização universitária atual 
influenciada por dois fatores principais: a implantação do processo de Bolonha ${ }^{4}$ e a mudança de contexto da própria instituição universitária.

De acordo com os professores investigados, o processo de Bolonha apresenta um novo paradigma para o ensino universitário, exigindo que as universidades europeias substituam "o paradigma do ensino para o paradigma da aprendizagem”, como explica Leite (2011). Isso quer dizer que o processo de Bolonha aponta que o centro do processo ensino-aprendizagem não é mais o professor e, sim, o aluno.

No contexto da universidade, os professores envolvidos apontam como elementos que interferem na organização universitária a democratização do ensino superior e os processos de avaliação institucional que incluíram a avaliação de desempenho dos professores universitários.

Sobre a democratização do ensino, para a entrevistada Vieira (2011), a abertura do ensino superior inseriu uma maior quantidade de alunos em sala de aula, com interesses diversos, ou seja, o perfil do aluno universitário hoje é um perfil diferente do que se tinha há algum tempo. A esse respeito Esteves (2011) afirma que:

Tradicionalmente a universidade formava apenas uma elite, estudantes que provinham todos de um mesmo grupo socioeconômico, sociocultural e, portanto, tinham objetivos e perspectivas de vida muito idênticas e procuravam todos bastante o mesmo na universidade. Evoluímos para uma situação que é nossa contemporânea em que felizmente as universidades se democratizaram, não apenas na quantidade de estudantes que acedem a elas, mas, também, na diversidade destes estudantes, portanto uns com projeto de vida muito claros, outros a procura ainda de que seja a própria universidade a ajudá-los a perspectivar o que podem vir a fazer da vida deles [...].

Outra categoria apresentada apontada pelos entrevistados foi que na avaliação institucional, marcada pela avaliação de desempenho docente,

${ }^{4}$ A Declaração de Bolonha é um documento assinado por ministros da educação de 29 países europeus (dentre eles, Portugal), em 29 de junho de 1999, em Bolonha na Itália (DECLARAÇÃo DE BOLONHA, 1999). 
aparece a indicação da formação pedagógica, que em geral é apontada como um dos elementos definidores da prática docente. Estrela (2011), relata que acompanhou o resultado de algumas dessas avaliações na universidade na qual atua, e que por meio dos inquéritos respondidos pelos alunos notou que eles reconheciam a competência científica e o domínio do conteúdo dos professores, mas apontavam que faltava uma preparação pedagógica desses professores. Na mesma direção, Mello (2011) explica que a avaliação de desempenho docente, com enfoque nas metodologias utilizadas pelos professores pode servir como um instrumento para mostrar aos professores o que a Instituição espera deles e, também, "pode criar estímulos à alteração das práticas", como explica o entrevistado.

Na dimensão formação pedagógica para a docência universitária, os fatores levantados geraram como categorias: a constituição de uma profissionalidade docente universitária e o papel do conhecimento pedagógico no exercício docente.

Quanto à constituição de uma profissionalidade docente universitária, Estrela (2011), aponta que "é o conjunto de saber-fazer e saberes exigidos pelo exercício profissional e orientado por um ideal que constitui o profissionalismo". Esteves (2011), complementa que a profissionalidade docente no ensino superior comporta a "[...] discussão pedagógica no que respeita ao que é a profissão docente, quais são as funções que lhe cabem e que competências são necessárias para desempenhar cada uma dessas funções".

A consciência da profissionalidade, de acordo com a opinião de Trindade (2011), levaria os professores do ensino superior a perceberem "[...] que também têm que assumir funções como docentes, não por acidente, mas como obrigação e compromisso". Consoante a essas concepções, Rodrigues (2011) explica que, em sua opinião, a profissionalidade do professor universitário deveria estar relacionada à capacidade:

[...] de fazer adquirir ao aluno o conhecimento de sua área disciplinar e, ao mesmo tempo, abrir as perspectivas pra ele ser capaz de, entrando na investigação ou não entrando na investigação, ter uma atitude de pesquisa a vida inteira e de formação a vida inteira e isto, eu acho que é uma 
profissionalidade que implica que ele tenha conhecimento de um conteúdo, que ele seja capaz de o dar, de o disponibilizar, mas, ao mesmo tempo, que tenha uma ideia pedagogicamente fundamentada sobre como é que ao longo da vida nós nos apropriamos de saberes sem professores.

Percebe-se que, para os entrevistados, a profissionalidade docente envolve competências e saberes específicos e particulares dessa profissão, que estão relacionados com o conhecimento pedagógico, como exposto na terceira seção deste trabalho.

Neste sentido, em relação ao papel do conhecimento pedagógico no exercício docente e na constituição da profissionalidade docente universitária, os professores entrevistados afirmam que ainda há certa resistência dos professores universitários em relação à "pedagogia”, pois estão muito calcados na ideia de que para ensinar é preciso apenas saber o conteúdo. Consideram que, sem saber, não se pode mesmo ensinar, mas alertam que também é preciso saber como ensinar, descobrir a melhor forma de os alunos aprenderem determinado conteúdo.

Nessa perspectiva, os professores portugueses ressaltam o conhecimento pedagógico como sendo tão importante quanto o conhecimento científico da área a ser ensinada. Porém, os entrevistados, em geral, destacam que é o conhecimento pedagógico que identifica o profissional como professor, trata-se do conhecimento específico da docência, como se pode observar na contribuição de Trindade (2011):

É o conhecimento pedagógico que confere singularidade à definição da docência como uma profissão [...]. É um conhecimento que nos é próprio, quer dizer, é um conhecimento que nos deverá permitir transitar de uma ação profissional ingênua para uma ação profissional informada.

Nessa questão, os entrevistados, fazendo uma análise entre a profissionalidade docente na educação básica e no ensino superior, expõem que há um núcleo comum, que é o ensino, isto é, seja na educação básica ou o ensino superior, os professores precisam ter a competência pedagógica e 
também o domínio do conteúdo do que se está a ensinar. Na realidade, o que muda é o contexto e os objetivos do ensino para cada nível.

Em relação ao ensino, um dos elementos distintos da educação básica e do ensino superior é o nível de desenvolvimento dos alunos. Sobre esta questão, Roldão (2011) expõe que o modo de ensinar na universidade não deve ser o mesmo da escola básica. Acredita que no ensino superior não se precisa enfatizar tanto o desenvolvimento do aluno, pois "[...] já não estamos com pessoas em desenvolvimento, já estamos com pessoas adultas, mas que têm um percurso de vida que temos que conciliar". Complementa que o objetivo da educação básica é fazer com que os alunos aprendam o essencial e, no ensino superior, é conseguir com que os alunos aprofundem os conhecimentos trabalhados.

O sentido de responsabilidade com relação ao desenvolvimento dos alunos no ensino superior, para Estrela (2011), é diferente do que como ocorre no ensino básico:

O professor universitário restringe-o mais aos aspectos cognitivos, ao desenvolvimento das capacidades e das atitudes e das competências que permitirão depois o aluno do ensino superior ser talvez um bom investigador, um bom profissional ou um bom divulgador das suas matérias". E acrescenta: "No ensino não universitário há mais explicitada uma responsabilidade até ética no desenvolvimento dos alunos e não só ética como também sócio-afectiva [...].

Observa-se também nas falas que o que distingue a profissionalidade do docente universitário em relação ao professor da educação básica é a estreita relação entre a investigação e o ensino, como afirma Estrela (2011):

De acordo com as missões da universidade, o professor universitário tem que, não só aprofundar o seu saber, como ser capaz de construir novo saber. E esse novo saber deveria incluir o saber pedagógico, isto é, o saber comunicar, divulgar e adaptar essa comunicação à heterogeneidade dos públicos a que se dirige. 
Sobre o compromisso com a pesquisa, as contribuições levantadas apontam que o professor universitário, em geral, é prestigiado socialmente e em termos de progresso na carreira, pelas publicações que realiza e pelo conhecimento que produz. Ou seja, o docente universitário, em Portugal, ainda é mais valorizado por ser um pesquisador, pelos artigos que publica e não por seu desempenho pedagógico em sala de aula.

As instituições de ensino superior e seus docentes, como salienta Rodrigues (2011), precisam compreender que "Ensinar não é só divulgar, quer dizer quando eu divulgo, eu escrevo um artigo, quem me lê que aprenda se quiser, agora, no ensino não é bem isto, é um pouco mais do que isto". Nessa medida, de acordo com Esteves (2011), a docência universitária "tem que assentar, quer em competências de investigação, quer em competências pedagógicas”. Tavares (2011) reforça esta premissa que é necessário entender o professor do ensino superior como um profissional docente e não apenas como um investigador.

A dimensão dos dispositivos de formação pedagógica para o docente universitário, compreende como categorias: a concepção da formação, a dinâmica coletiva e reflexiva da formação e o apoio institucional para a formação.

A respeito da concepção da formação, todos os professores entrevistados concordam que um programa de formação de professores universitários não pode sustentar-se numa visão tradicional e aplicacionista de formação, baseada num paradigma conservador, no qual os professores participam de cursos de curta duração, ministrados por especialistas para lhes dizer "como é que têm que fazer", para falar sobre algo que não atende às suas reais necessidades. Essa estruturação segundo Vieira (2011), “[...] não é a forma de provocar uma mudança mais sustentável ao longo do tempo". Ainda conforme a participante, esse tipo de formação tem muito pouco valor se não for acompanhado de outras dimensões. Para Mouraz (2011), num processo formativo, "[...] o essencial é exatamente a questão pedagógica, ou seja, antes de eu ser professor de Estruturas, que é uma área da Engenharia, eu sou professor, pronto. E essa é a dimensão do ser professor que está em evidência".

Por conseguinte, os professores entrevistados salientam que uma formação para o professor universitário deve partir, necessariamente, dos 
interesses, da realidade concreta desses professores, das situações, das dificuldades enfrentadas, problematizando as suas práticas, num constante processo reflexivo, atendendo a um paradigma inovador.

No ensino superior, Pinto (2011) afirma que a "[...] formação pedagógica tem que estar a serviço do ensino do domínio científico". Para a entrevistada, a pedagogia no ensino superior deve ser apresentada aos docentes como uma ferramenta útil para ensinar seus conteúdos para que seus alunos aprendam melhor. Enfatiza que "[...] só se aprende aquilo que é significativo e só é significativo aquilo que nos é útil”. Nessa perspectiva, Estrela (2011) expõe que os professores universitários "[...] não querem grandes formulações teóricas que sintam desligadas de sua realidade, querem centrar-se na sua realidade para, então, a partir dela recolher os instrumentos teóricos que lhe permitam pensá-la”. Roldão (2011), salienta que a formação pedagógica de professores universitários precisa ser "alguma coisa que se encaixe na vida cotidiana da instituição e que se configure em torno de resultados com utilidades práticas na docência [...]".

Neste sentido, para Alarcão (2011), assim como é um consenso no campo educacional que a aprendizagem, para ser significativa para o aluno, precisa partir da realidade, o mesmo princípio precisa ser considerado para os professores, por isso frisa que: "[...] se estamos a lidar com professores que são investigadores é muito bom partir de problemas". E complementa que é preciso "[...] incentivar os mecanismos que eles adotam na investigação nas suas áreas científicas, para com esse mesmo espírito de indagação, se debruçarem sobre o seu ensino".

Porém, conforme a segunda categoria, os professores investigadores entrevistados alertam que a reflexão, o debate, o trabalho coletivo e a partilha entre os professores a partir de suas experiências docentes precisam estar calçados em um referencial teórico que servirá como apoio às discussões. Fernandes (2011) afirma que "a aprendizagem, o conhecimento tem que ser feita/construída nessa relação, porque não se reflete no vazio, sem conhecimento, sem conteúdo".

Nóvoa (2011) coloca que é preciso que a universidade e o docente tenham 
a capacidade de poder instituir grupos de reflexão com os outros colegas, de poder ter momentos de reflexão sobre o trabalho, ter momentos em que as pessoas fazem inquéritos aos estudantes e perguntam as opiniões dos estudantes e procuram trabalhar sobre estas suas opiniões, ter a capacidade de poder ter contato com novas tecnologias, com coisas que funcionem. Pra mim, um programa de formação não é propriamente organizar um curso, organizar um semestre, é tentar encontrar uma rotina de funcionamento, de trabalho em que possa haver dentro da universidade pessoas que possam ajudar cada um dos professores neste percurso.

Um dispositivo de formação pedagógica de professores universitários, segundo Roldão (2011) alerta que além de funcionar como um grupo de discussão, de reflexão sobre o contexto e as práticas dos docentes, conduzido por alguém responsável por organizar o processo, deveria ter duas intencionalidades principais. Uma primeira intenção seria romper com a disciplinaridade, de forma que os professores se sintam pertencentes a um grupo, de forma que o fundamento pedagógico se torne algo comum entre todos, discutido conjuntamente, independentemente das áreas de conhecimento.

Outra intenção da formação pedagógica apontada por Roldão (2011) é a promoção de parcerias de trabalho docente, nas quais os professores universitários se envolvam em atividades e tarefas comuns, trabalhando em equipe, como a realização de pesquisas, de seminários, de aulas, de projetos com os alunos, entre outros.

A formação pedagógica é defendida por Fernandes (2011), pois no ensino superior, sobretudo, "[...] deve se assentar num modelo que fomente a construção coletiva do conhecimento e essa construção coletiva do conhecimento só se faz pelas vias da construção dos espaços das partilhas, de debates, de reflexão e de sistematização".

Os professores entrevistados apregoam que, como a investigação é um elemento inerente à atividade docente no ensino superior, um programa de formação docente nesse nível de ensino precisa aproveitar esse viés, instigando os professores universitários "a olhar para o seu trabalho pedagógico com a mesma curiosidade com que olham para os fenômenos de seu campo 
científico", como colocou Esteves (2011). A esse respeito, Nóvoa (2011) complementa que "da mesma maneira que nós temos seminários de discussão científica sobre temas científicos, também me parece normal que haja seminários para a discussão de temas pedagógicos [...]".

A experiência dos docentes, suas vivências no cotidiano da sala de aula, é citada pela grande maioria dos entrevistados como um componente essencial no processo de formação pedagógica. De acordo com Vieira (2011),

Se o curso integrar mais experiências profissionais [...] isso não só beneficia directamente os alunos com quem nós trabalhamos, mas também beneficia a nós porque nos obriga a pensar sistematicamente sobre aquilo que estamos a fazer, motiva-nos a fazer leituras sobre isso, etc.

Como subsídio para compor um programa de formação do professor universitário, Esteves (2011), aponta que, além das expectativas dos docentes, também se deve levar em consideração a avaliação que os estudantes fazem da instituição e dos professores, bem como o projeto de desenvolvimento da instituição universitária. Sobre esse aspecto, Caetano (2011), afirma que a formação pedagógica do docente universitário deveria ser organizada "de acordo com as características das universidades, das próprias áreas [...] não é só uma coisa conceitual, teórica, abstrata, mas fazer uma coisa que seja articulada com seu trabalho".

Os entrevistados ressaltam que a flexibilidade e o princípio de se partir das necessidades dos docentes não excluem uma estruturação e sistematização do processo formativo. Para Fernandes (2011) e Caetano (2011), por exemplo, inicialmente, deve haver alguém que se responsabilize por organizar os temas e os materiais de estudo, apreender os interesses do grupo, provocar as discussões, entre outras, a quem denominam de "formador". Observa-se que a ideia central da formação pedagógica para professores do ensino superior, como explica Vieira (2011), é "[...] associar coisas que tradicionalmente estavam distanciadas: o ensino, a investigação e o desenvolvimento profissional”. 
De acordo com os professores entrevistados, o docente universitário precisa perceber que não é necessário deixar de fazer suas pesquisas para se dedicar às questões pedagógicas e vice-versa. O seu próprio ensino, sua prática pedagógica pode e deve ser objeto de reflexão, de estudo, de investigação e gerar novos conhecimentos. Ao fazer isso, está investindo em seu próprio desenvolvimento profissional, em especial, por meio da integração do ensino, da investigação e da aprendizagem para crescer profissionalmente. Mas, para tal, é preciso o envolvimento e o comprometimento dos professores universitários na busca de uma docência significativa que leve a produção de conhecimento e que supere a reprodução de conteúdos sem sentido para os estudantes.

Sobre a questão de como envolver os professores numa formação pedagógica, os participantes concordam que existem basicamente duas vias: uma via institucional e uma via da própria organização da formação.

Os professores pesquisadores investigados acreditam que um dispositivo de formação pedagógica precisa ter o apoio institucional, mas que o ideal é que a instituição incentive a formação, de modo que a participação dos professores na formação pedagógica seja voluntária, pois, segundo Leite (2011) “[...] ninguém consegue formar ninguém se a pessoa não quiser ser formada".

As contribuições dos investigados apontam que a formação pedagógica poderia começar por uma exigência institucional e, à medida que os docentes perceberem que o conhecimento pedagógico é importante e útil, que os auxilia, e facilita o ensino dos conteúdos científicos aos alunos, vão sentindo a necessidade de refletir cada vez mais sobre sua prática e começam a procurar, voluntariamente, o processo de formação pedagógica. Rodrigues (2011), baseada em sua experiência com a formação de professores, relata que "[...] é interessante constatar que quando são confrontados com algumas práticas e alguns dispositivos reconhecem que estas práticas e estes dispositivos de teor pedagógico lhes são úteis".

O apoio institucional, na opinião de Rodrigues (2011) deveria ser no sentido de fazer com que o professor entendesse, 
[...] por um lado, que isso ébom pra mim, mas é preciso que eu também percebesse que quem me governa, quem me gere, quem me paga, quem me comanda também reconhece que é bom eu ir, que é bom eu ter ido e que essa articulação entre eu ter ido porque me aproprio de um saber novo e reconhecerem que tenho saber novo e que agora posso ser melhor, funciona.

Porém, Trindade (2011) alerta que o apoio institucional deve ser o de proporcionar condições para que o projeto de formação se desenvolva e não o de controlar a discussões e as reflexões dos professores no decorrer da formação. Para o entrevistado, a instituição deveria

Intervir, animando a reflexão, confrontando-nos com os problemas, mas respeitando a margem de autonomia profissional que aos professores diz respeito e permitindo que sejam os professores a encontrar soluções exequiveis e consequentes no que à sua autoformação diz respeito.

Entre as condições que a instituição deveria oferecer aos professores universitários está o "tempo". Os professores entrevistados colocam a falta de tempo como um grande obstáculo para que os professores universitários se dediquem mais a uma formação pedagógica. Relatam que, como há uma quantidade excessiva de aulas e alunos com os quais têm que se preocupar, também há grande cobrança em relação ao número de publicações e de projetos dos quais precisam participar (para progredir na carreira e para gerar financiamento às instituições), e o ensino vai ficando em segundo plano. Então, como precisam optar, dedicam uma parcela maior do tempo à investigação (que lhes dá maior retorno social e financeiro) e, o tempo que resta é dedicado ao ensino, no sentido de preparar-se para tal. Os professores entrevistados salientam que a investigação (publicações) e o ensino (desempenho pedagógico) deveriam ser valorizados com igualdade pela instituição.

Essa perspectiva institucional alia-se à necessidade da própria organização da formação pelos professores. Neste sentido, Queiroz e Mello (2011) afirmam que a instituição precisa "criar um sentido de urgência na mudança", pois os docentes universitários precisam estar motivados a se envolverem em processos de formação e um dispositivo de motivação é que a aprendizagem, proporcionada pelo processo formativo, seja significativa 
para sua atuação profissional. Como ressalta Caetano (2011), de modo que os professores percebam que "[...] aquilo não é um tempo perdido [...]". E, em complemento, Esteves (2011) afirma que é preciso levar os docentes do ensino superior a terem uma atitude de mudança, ou seja, "vontade de inovar em função de um fim que se quer atingir que é melhorar a qualidade da aprendizagem dos alunos e a partir daí, então, tomar decisões [...]".

Por outro lado, ao mesmo tempo em que os docentes investigados afirmam a necessidade do incentivo institucional, denotam também que é preciso que os professores universitários despertem para a realidade atual das salas de aula, da urgência de mudança e adaptação às novas exigências da sociedade, da universidade e do perfil dos alunos.

\section{Considerações finais}

A partir do exposto, em síntese, as entrevistas com os professores portugueses frisam que é importante que numa formação pedagógica de professores universitários: a) as temáticas desenvolvidas partam das necessidades formativas dos próprios docentes, de suas dúvidas e problemas vividos em sala de aula; $b$ ) as práticas pedagógicas dos docentes e a reflexão sobre essas práticas norteiem todo o processo de formação; c) a formação pedagógica propicie a partilha de saberes e sua construção coletiva; d) a formação pedagógica se organize de tal forma que o professor universitário perceba que a pedagogia é aliada do conhecimento científico, que na docência, ambos precisam andar lado a lado para um ensino e uma aprendizagem de qualidade; e) é importante que o professor perceba o apoio institucional como suporte para a formação pedagógica e para proporcionar condições de realização de novas práticas docentes.

Nota-se que as concepções apresentadas pelos entrevistados confirmam como é necessária a formação pedagógica do professor universitário para uma prática pedagógica inovadora. A análise das concepções da academia portuguesa em relação à formação pedagógica permitiu perceber que há dificuldades, enfrentamentos e que as percepções de ambas as realidades 
universitárias, portuguesa e brasileira, são semelhantes (JUNGES, 2013). Destacou-se a importância das questões pedagógicas para se atender ao novo contexto vivido pela universidade, pois os docentes universitários precisam compreender o valor da articulação dos conhecimentos científicos aos conhecimentos pedagógicos para o processo de ensino e aprendizagem e, para tanto, precisam investir numa formação pedagógica.

Nesse sentido, os dados levantados revelam que as instituições de ensino superior precisam tornar-se o lócus dessa formação, a partir de uma pedagogia universitária. Cabe aqui registrar a preocupação de Nóvoa (2007, p. 8), que sintetiza esse ponto a ser considerado na organização de uma formação pedagógica de professores universitários: "É inútil apelar à reflexão se não haver uma organização das escolas que a facilite. É inútil reivindicar uma formação mútua, inter-pares, colaborativa, se a definição das carreiras docentes não for coerente com este propósito". E acrescenta

É inútil propor uma qualificação baseada na investigação e parcerias entre escolas e instituições universitárias se os normativos legais persistirem em dificultar esta aproximação. Numa palavra, não vale a pena repetir intenções que não tenham uma tradução concreta em acções e compromissos políticos.

Neste sentido, as contribuições da pesquisa apontam para a necessidade da proposta de formação de professores universitários estar fundamentada numa perspectiva inovadora, colaborativa e com concepções claras acerca dos objetivos do processo de aprendizagem dos estudantes e, em especial, do papel esperado do professor como mediador do conhecimento. A pedagogia universitária é um campo ainda em construção não somente no Brasil, mas também em Portugal, e que precisa de maior atenção dos gestores das instituições e da política do ensino superior.

\section{Referências}

ALARCÃO, I. Entrevista sobre o que pensam os professores portugueses, concedida a Kelen dos Santos Junges. Aveiro: 9 mai. 2011. 
BEHRENS, M. A. O paradigma da complexidade na formação e no desenvolvimento profissional de professores universitários. Educação, Porto Alegre, ano XXX, n. 3, p. 439-455, set./dez. 2007. Disponível em: <http://revistaseletronicas.pucrs.br/fo/ojs/index.php/faced/issue/view/47>. Acesso em: 10 jul. 2010.

CAETANO, A. P. Entrevista sobre o que pensam os professores portugueses concedida a Kelen dos Santos Junges. Lisboa: 20 abr. 2011.

DECLARAÇÃO DE BOLONHA. Declaração conjunta dos Ministros da Educação europeus reunidos em Bolonha em 19 de Junho de 1999. Bolonha, 1999. Disponível em: <http://www.aauab.pt/bolonha/declaracaobolonha.pdf>. Acesso em: 10 ago. 2011.

ESTEVES, M. Para a excelência pedagógica do ensino superior. Sísifo - Revista de Ciências da Educação, Lisboa, n. 7, p. 101-109, set./dez. 2008.

ESTEVES, M. Entrevista sobre o que pensam os professores portugueses, concedida a Kelen dos Santos Junges. Lisboa: 13 abr. 2011.

ESTRELA, A. Teoria e prática de observação de classes: uma estratégia de formação de professores. 2. ed. Lisboa: Instituto Nacional de Investigação Científica, 1986. ESTRELA, M. T. Entrevista sobre o que pensam os professores portugueses, concedida a Kelen dos Santos Junges. Lisboa: 15 abr. 2011.

FERNANDES, P. Entrevista sobre o que pensam os professores portugueses, concedida a Kelen dos Santos Junges. Porto: 10 mai. 2011.

JUNGES, K. S. Desenvolvimento profissional de professores universitários: caminhos de uma formação pedagógica inovadora. 2013. 221f. Tese (Doutorado em Educação) — Pontifícia Universidade Católica do Paraná, Curitiba, 2013.

LEITE, C. Entrevista sobre o que pensam os professores portugueses, concedida a Kelen dos Santos Junges. Porto: 10 mai. 2011.

MELLO, R. Q. Entrevista sobre o que pensam os professores portugueses, concedida a Kelen dos Santos Junges. Lisboa: 19 mai. 2011.

MOURAZ, A. Entrevista sobre o que pensam os professores portugueses, concedida a Kelen dos Santos Junges. Porto: 10 mai. 2011. 
NÓVOA, A. Entrevista sobre o que pensam os professores portugueses, concedida a Kelen dos Santos Junges. Lisboa: 13 abr. 2011.

NÓVOA,A. Oregresso dosprofessores. In:CONFERÊNCIADE DESENVOLVIMENTO PROFISSIONAL DE PROFESSORES PARA A QUALIDADE E PARA A EQUIDADE DA APRENDIZAGEM AO LONGO DA VIDA, 2007, Lisboa. Anais... Lisboa: Presidência Portuguesa do Conselho da União Europeia, 2007. p. 21-28.

PINTO, P. R. Entrevista sobre o que pensam os professores portugueses, concedida a Kelen dos Santos Junges. Lisboa: 27 mai. 2011.

RODRIGUES, A. Entrevista sobre o que pensam os professores portugueses, concedida a Kelen dos Santos Junges. Lisboa: 15 abr. 2011.

ROLDÃO, M. C. Entrevista sobre o que pensam os professores portugueses, concedida a Kelen dos Santos Junges. Lisboa: 4 mai. 2011.

TAVARES, J. Entrevista sobre o que pensam os professores portugueses, concedida a Kelen dos Santos Junge. Aveiro: 9 mai. 2011.

TRINDADE, R. Entrevista sobre o que pensam os professores portugueses, concedida a Kelen dos Santos Junges. Porto: 10 mai. 2011.

VIEIRA, F. Entrevista sobre o que pensam os professores portugueses, concedida a Kelen dos Santos Junges. Braga: 12 mai. 2011.

Recebido: 10/07/2017

Received: 07/10/2017

Recibido: 10/07/2017

Aprovado: 30/09/2017 Approved: 09/30/2017 Aprobado: 30/09/2017 